\title{
IMPUlSE Mode OF NATURAL Gas FLOW AND ITS EFFECT ON METERING SYSTEM ACCURACY
}

\author{
Roman Fedoryshyn, Fedir Matiko, Oleh Pistun, Roman Brylynskyi \& Oleh Masniak
}
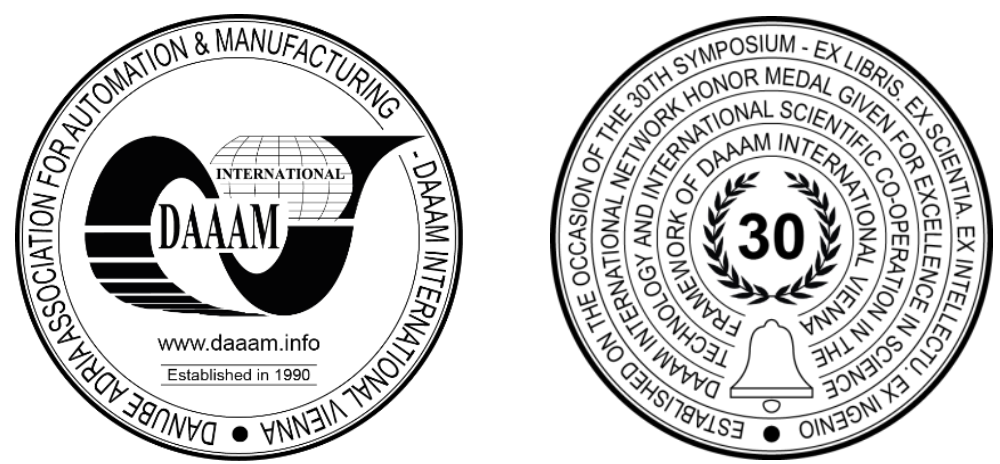

This Publication has to be referred as: Fedoryshyn, R[oman]; Matiko, F[edir]; Pistun, O[leh]; Brylynskyi, R[oman] \& Masniak, O[leh] (2020). Impulse Mode of Natural Gas Flow and Its Effect on Metering System Accuracy, Proceedings of the 31st DAAAM International Symposium, pp.0956-0962, B. Katalinic (Ed.), Published by DAAAM International, ISBN 978-3-902734-29-7, ISSN 1726-9679, Vienna, Austria

DOI: $10.2507 / 31$ st.daaam.proceedings. 133

\begin{abstract}
The paper analyses a natural gas flow metering system based on a rotary meter with an impulse mode of gas flow caused by the peculiarities of the water-heating boiler operation. The mathematical model of the gas metering system was developed on the basis of the gas flow rate equation and the heat conservation law. The modelling of the metering system in impulse modes of gas flow was carried out in order to evaluate the gas temperature measurement error caused by the temperature transducer lag and the corresponding errors of flow rate and volume measurement. The results of the modelling of these errors were analysed, and the ways to improve the accuracy of natural gas metering were proposed.
\end{abstract}

Keywords: Natural gas; Measurement; Error; Modelling.

\section{Introduction}

The flow rate and volume of natural gas can be measured using a variety of methods. A metering system, as a rule, in addition to a flow rate device (gas meter), comprises gas temperature and pressure measuring transducers, as well as a microprocessor computing device (corrector) to reduce the gas volume to standard conditions. The total accuracy of gas flow rate and volume measurement depends on the accuracy of each component of the metering system [1]. The negative factor that affects the accuracy of natural gas metering is the additional error of gas temperature measurement. This error can be caused by the difference between the gas temperature and the ambient temperature, variations in the gas temperature and flow rate. I can also arise in impulse modes of gas flow.

A specific feature of natural gas metering at heat-generating facilities (boiler houses, cogeneration plants, thermal power stations) is a significant difference between the gas flow temperature and the ambient temperature. Such a difference in temperature commonly occur during winter, when cold gas flows from the outdoors into a warm boiler house, where the metering unit is located. At heat-generating facilities, there can be variations of the gas flow rate caused by operation modes of the gas equipment, namely of the water-heating and steam boilers. In such conditions, the gas temperature measurement error can be rather large, and the influence of the temperature conditions of the metering system operation on the accuracy of natural gas flow rate and volume measurement can be quite significant. 
One of the components of the gas temperature measurement error is the error caused by the temperature transducer lag during the variations of the flow parameters (the temperature and flow rate) occurring in impulse modes of the metering systems. Taking into consideration and elimination of this component of the error, as well as of other gas temperature measurement errors, is an important step towards the improvement of the natural gas metering accuracy at heat-generating facilities.

\section{Analysis of recent studies}

The effect of temperature conditions of the natural gas metering system operation on the accuracy of its flow rate and volume measurement has been discussed in the studies [2] - [5]. In particular, [2] presents a classification of additional errors of gas temperature measurement and describes the errors caused by the heat exchange between the temperature transducer case and the pipe wall $\left(\Delta T_{T}\right)$, heat exchange between the pipe wall and the ambient air $\left(\Delta T_{x}\right)$, the error caused by a temperature drop as the gas is throttled through the pressure differential device $\left(\Delta T_{t h r}\right)$, etc. However, these researches did not pay sufficient attention to the study of dynamic characteristics of temperature transducers in the assembly units and their influence on the accuracy of gas flow rate and volume measurement at varying flow parameters (the temperature and flow rate).

\section{Goal of research}

The research aims at studying the influence of the impulse modes of gas flow in metering systems on the accuracy of gas flow rate and volume measurement. The impulse mode is an operation mode of a metering unit at which there occur interruptions of gas flow and, thereat, the amplitudes of flow rate impulses and the period and duration of the impulses can be different. In order to analyze the flow temperature measurement errors the modelling of the gas metering system in impulse operation modes should be carried out for different parameters taking into consideration the temperature transducer lag. Another objective is to propose the measures for improvement of the gas metering accuracy at heat-generating facilities, which are characterized by significant differences between the gas temperature and the ambient temperature, and where there are impulse modes of gas flow.

\section{Presentation of main material}

For a natural gas metering system installed in a boiler house, when the gas flow rate in the pipe is zero, the gas temperature in the stationary state is equal to the temperature of the ambient air in the boiler house. Switching on a water-heating boiler, or any other gas-consuming system, results in an abrupt rise of gas flow rate up to a certain nominal value. The temperature of the gas flow coming from the outdoors gradually changes and by the end of the transient process reaches a certain steady-state value. During dynamic variation of the gas temperature, the value measured by the temperature transducer is a little different from the actual temperature due to the temperature signal lag. The difference between the measured temperature value and the actual temperature of the flow in transient modes is the error caused by the temperature transducer lag $\left(\Delta T_{\text {lag }}\right)$. The error $\left(\Delta T_{\text {lag }}\right)$ correspondingly leads to the errors of gas flow rate $(\Delta F)$ and volume $(\Delta V)$ measurement.

Switching off the water-heating boiler leads to a sudden termination of gas consumption, and the gas temperature in the pipe gradually reaches the ambient temperature in the boiler house. Thereat, the measured gas temperature lags behind the actual gas temperature due to the temperature transducer lag, and this will cause the error $\left(\Delta T_{\text {lag }}\right)$, but this time with an opposite sign. However, there will be no $\Delta F$ and $\Delta V$ errors in this case, as after the gas consumption has stopped, the gas flow rate, as measured by the metering system, will be equal to zero and no computations will be carried out by the corrector. Therefore, the temperature transducer lag will have an effect on the accuracy of gas flow rate and volume measurement only at turning on the gas feeding.

\subsection{Development of gas metering system model}

For modelling the natural gas metering system and the error $\Delta T_{\text {lag }}$ in it, we will use the mathematical model developed on the basis of the heat conservation law and the gas flow rate equation for a long pipe with a turbulent flow, using the analytical formulae from [6] - [10].

The equation of heat conservation for the gas flowing in the pipe upstream of the metering system will be:

$$
\frac{d q_{p}}{d t}=Q_{\text {in }}-Q_{\text {out }}-Q_{\text {loss }},
$$

where $q_{p}$ is the amount of heat in the gas located in the pipe (J); $Q_{i n}$ is the amount of heat coming with the gas at the pipe input (J/s); $Q_{\text {out }}$ is the amount of heat that goes out with the gas at the pipe output (J/s); $Q_{\text {loss }}$ is the amount of heat that is lost from the gas flow to the ambient air through the pipe wall (W). 
The amount of heat in the gas located in the pipe is defined by the equation:

$$
q_{p}=m_{\text {gas }} \cdot c_{p . g a s} \cdot T_{\text {gas }}
$$

where $m_{\text {gas }}$ is the mass of gas in the pipe $(\mathrm{kg}) ; c_{\text {p.gas }}$ is the specific heat capacity of the gas $(\mathrm{J} /(\mathrm{kg} \cdot \mathrm{K}))$; $T_{\text {gas }}$ is the gas temperature in the pipe. The amount of heat coming with the gas at the pipe input is defined by the equation:

$$
Q_{\text {in }}=F_{\text {m.gas }} \cdot c_{\text {p.gas }} \cdot T_{\text {gas } 1}
$$

where $F_{\text {m.gas }}$ is the mass flow rate of the gas $(\mathrm{kg} / \mathrm{s}) ; T_{\text {gas } 1}$ is the gas temperature at the pipe input $(\mathrm{K})$. The amount of heat that goes out with the gas at the pipe output is defined by the equation:

$$
Q_{\text {out }}=F_{\text {m.gas }} \cdot c_{\text {p.gas }} \cdot T_{\text {gas } 2}
$$

where $T_{\text {gas } 2}$ is the gas temperature at the pipe output $(\mathrm{K})$. The amount of heat that is lost from the gas flow to the ambient air through the pipe wall is defined by the equation:

$$
Q_{\text {loss }}=K_{L} \cdot L \cdot\left(T_{\text {gas }}-T_{\text {air }}\right)
$$

where $K_{L}$ is the coefficient of linear heat transfer from the gas flow to the ambient air $(\mathrm{W} /(\mathrm{m} \cdot \mathrm{K}))$; $L$ is the pipe length $(\mathrm{m}) ; T_{\text {air }}$ is the ambient air temperature $(\mathrm{K})$. The coefficient of linear heat transfer from the gas flow to the ambient air $K_{L}$ is calculated according to [6]. The volumetric flow rate of gas in the pipe can be described by the following equation:

$$
A \cdot \frac{d F_{g a s}}{d t}+F_{g a s}^{2}=k^{2} \cdot \frac{p_{1}-p_{2}}{\rho_{g a s}},
$$

where $A$ and $k$ are coefficients that take into account the dimensions of the pipe; $\rho_{g a s}$ is the gas density at operating conditions $\left(\mathrm{kg} / \mathrm{m}^{3}\right) ; p_{1}$ is the gas pressure at the pipe input $(\mathrm{Pa}) ; p_{2}$ is the gas pressure at the pipe output $(\mathrm{Pa}) ; F_{\text {gas }}$ is the volumetric flow rate of gas at operating conditions $\left(\mathrm{m}^{3} / \mathrm{s}\right)$.

The following two assumptions are made during development of the mathematical model:

- the gas density along the pipe is constant;

- the gas temperature in the pipe is equal to the gas temperature at the pipe output $\left(T_{\text {gas }}=T_{\text {gas } 2}\right)$.

By joining the equations (1) - (6) the mathematical model of the gas temperature mode in the pipe is obtained in the form of the following system of differential equations:

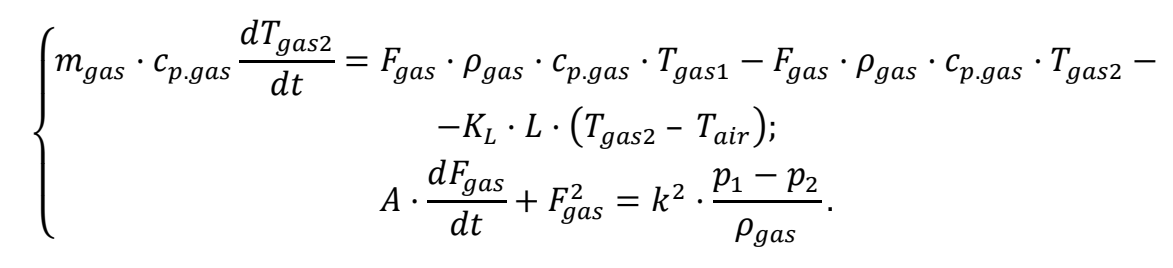

The volumetric flow rate of gas at operating conditions is reduced to standard conditions according to the following formula:

$$
F_{\text {s.gas }}=F_{\text {gas }} \cdot \frac{\rho_{\text {gas }}}{\rho_{\text {s.gas }}},
$$

where $F_{\text {s.gas }}$ is the gas flow rate at standard conditions $\left(\mathrm{m}^{3} / \mathrm{s}\right) ; \rho_{\text {s.gas }}$ is the gas density at standard conditions $\left(\mathrm{kg} / \mathrm{m}^{3}\right)$. Natural gas density at operating conditions is calculated as follows:

$$
\rho_{\text {gas }}=\rho_{\text {s.gas }} \cdot \frac{p_{\text {gas }} \cdot T_{\text {s.gas }}}{p_{\text {s.gas }} \cdot T_{\text {gas }} \cdot K},
$$

where $p_{\text {gas }}$ is the gas pressure at operating conditions $(\mathrm{Pa}) ; T_{\text {gas }}$ is the gas temperature at operating conditions $(\mathrm{K}) ; p_{\text {s.gas }}$ is the gas pressure at standard conditions $(101,325 \mathrm{~Pa}) ; T_{\text {s.gas }}$ is the gas temperature at standard conditions $(293.15 \mathrm{~K}) ; K$ is the compressibility coefficient for natural gas. 
The model of the temperature transducer was applied in the form of the following transfer function to simulate the lag of the measured signal of gas temperature:

$$
W_{T T}(s)=\frac{1}{T_{T T} \cdot s+1},
$$

where $W_{T T}(s)$ is the transfer function of the temperature transducer; $s$ is the Laplace operator; $T_{T T}$ is the time constant of the temperature transducer. Equations (7) - (10) make the mathematical model of the natural gas metering system.

\subsection{Modelling of gas metering system}

The modelling was carried out for the metering system on the basis of the rotary meter KVR-1 G-250 having parameters presented in Table 1. This system was installed in the boiler house and operates in the impulse mode of gas flow due to the mode of gas consumption by the water-heating boiler. The simplified installation diagram for the gas meter is shown in Fig. 1.

\begin{tabular}{|l|c|}
\hline \multicolumn{1}{|c|}{ Parameter name } & Parameter value \\
\hline Fluid type & natural gas \\
\hline Absolute pressure of the gas, $\mathrm{kPa}$ & 380 \\
\hline Gas temperature, ${ }^{\circ} \mathrm{C}$ & +19.04 \\
\hline Gas flow rate reduced to standard conditions, $\mathrm{m}^{3} / \mathrm{h}$ & 110.00 \\
\hline Temperature of the ambient air, ${ }^{\circ} \mathrm{C}$ & +28 \\
\hline Pipe internal diameter, $\mathrm{mm}$ & 80 \\
\hline
\end{tabular}

Table 1. Parameters of the natural gas metering system

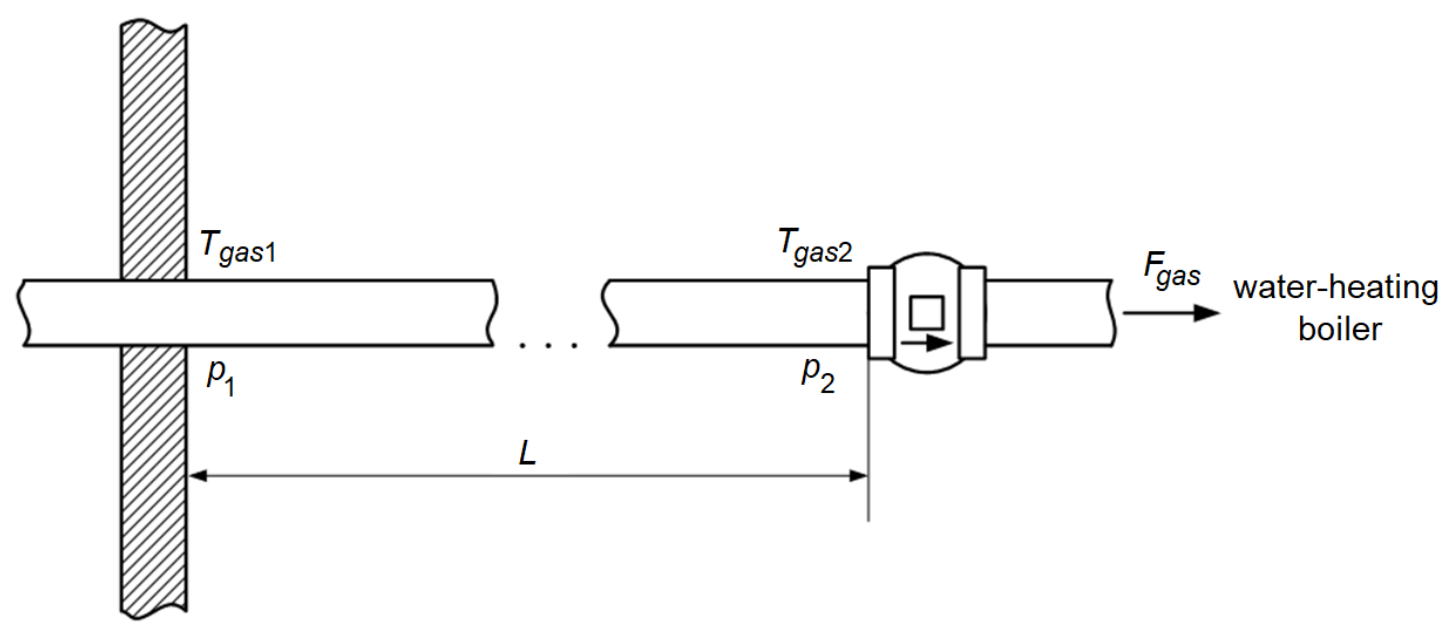

Fig. 1. Simplified installation diagram for the gas meter

The mathematical model of the metering system in the form of a structural diagram in SIMULINK is presented in Fig. 2. In this diagram, the impulse signal of the gas flow rate at operating conditions (block Impulse F_o) is supplied to the MATLAB Function block and then to Gain block where the first equation of system (7) is implemented. The integrator (Integrator1) outputs the actual gas temperature signal at the place of the temperature transducer installation. The block W_TT1 implements the transfer function of the temperature transducer and outputs the signal of the measured gas temperature with a lag. This signal is supplied into the blocks ro_o2, Product1 and Gain2 where equations (8), (9) are implemented and thereby we obtain the signal of the gas flow rate reduced to standard conditions, based on the measured gas temperature.

The following symbols are used in the diagram: T1 is the gas temperature at the place where the pipe enters the boiler house; T2 is the gas temperature at the place of the temperature transducer installation; Tair is the temperature of the ambient air in the boiler house; dT_lag is the error of gas temperature measurement caused by the temperature transducer lag; $\mathrm{dF} \_\mathrm{s}$ is the error of gas flow rate measurement caused by the error $\Delta \mathrm{Tlag}$; $\mathrm{dV} \_\mathrm{s}$ is the error of gas volume measurement resulting from the error $\Delta$ Tlag.

The impulse signal of the gas flow rate variation is supplied to the input of the model. The duration of impulses and pauses is $15 \mathrm{~min}$. The time constant of the temperature transducer is $1 \mathrm{~min}$. The modelling results are presented as graphs in Fig. 3, 4. 


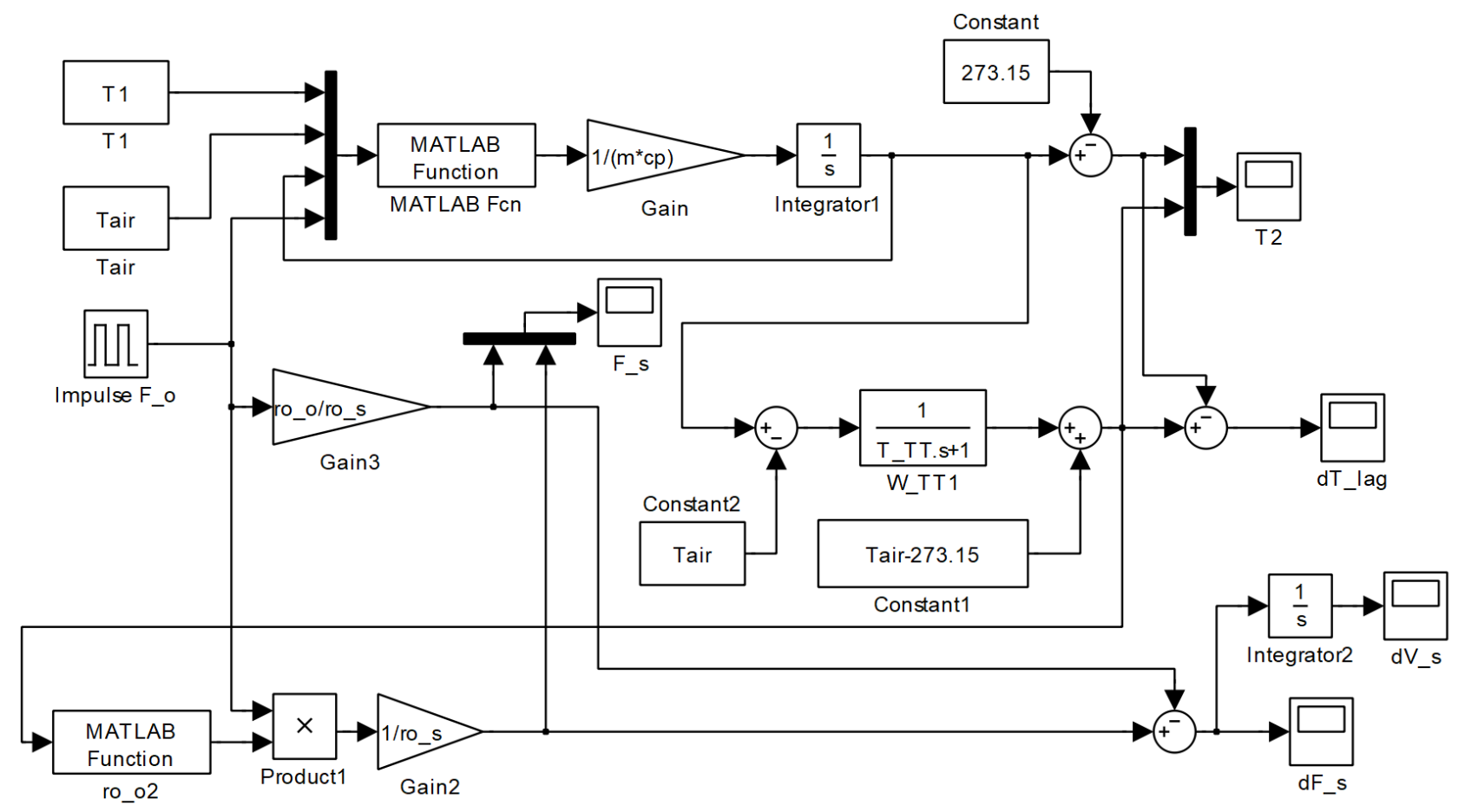

Fig. 2. Structural diagram of the mathematical model of the natural gas metering system in SIMULINK
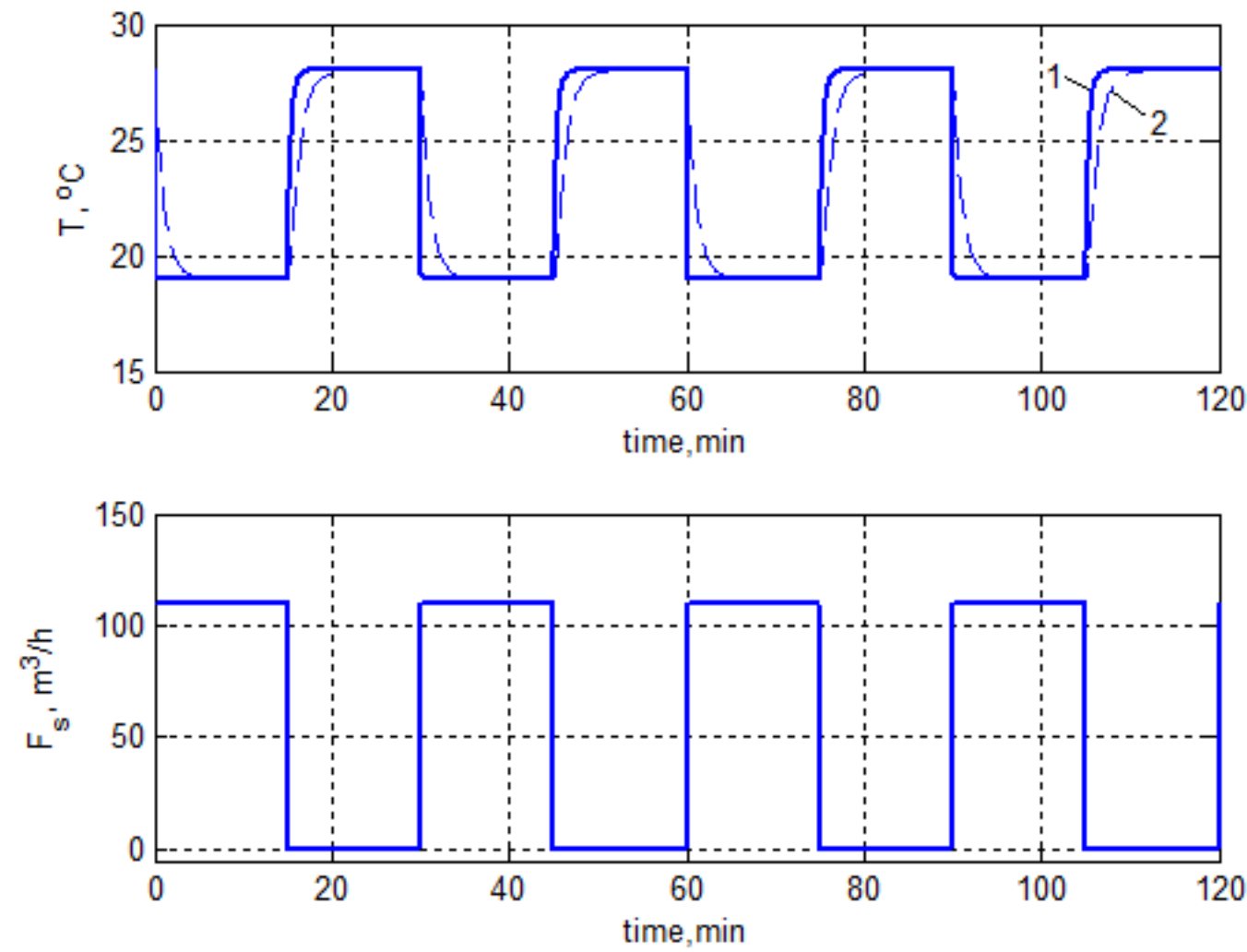

Fig. 3. Variation of the gas flow rate and temperature: 1 - actual value of the gas temperature; 2 - measured value of the gas temperature

The modelling results (Fig. 4) show that in an impulse mode of the metering unit operation when the gas flow temperature is lower than the ambient temperature $\left(T_{\text {gas }}<T_{\text {air }}\right)$, the error $\Delta T_{\text {lag }}$ at turning on the gas feeding is positive, and the errors $\Delta F_{s}$ and $\Delta V_{s}$ are negative. This means that at the gas metering unit there is an underestimated volume of the consumed gas. 

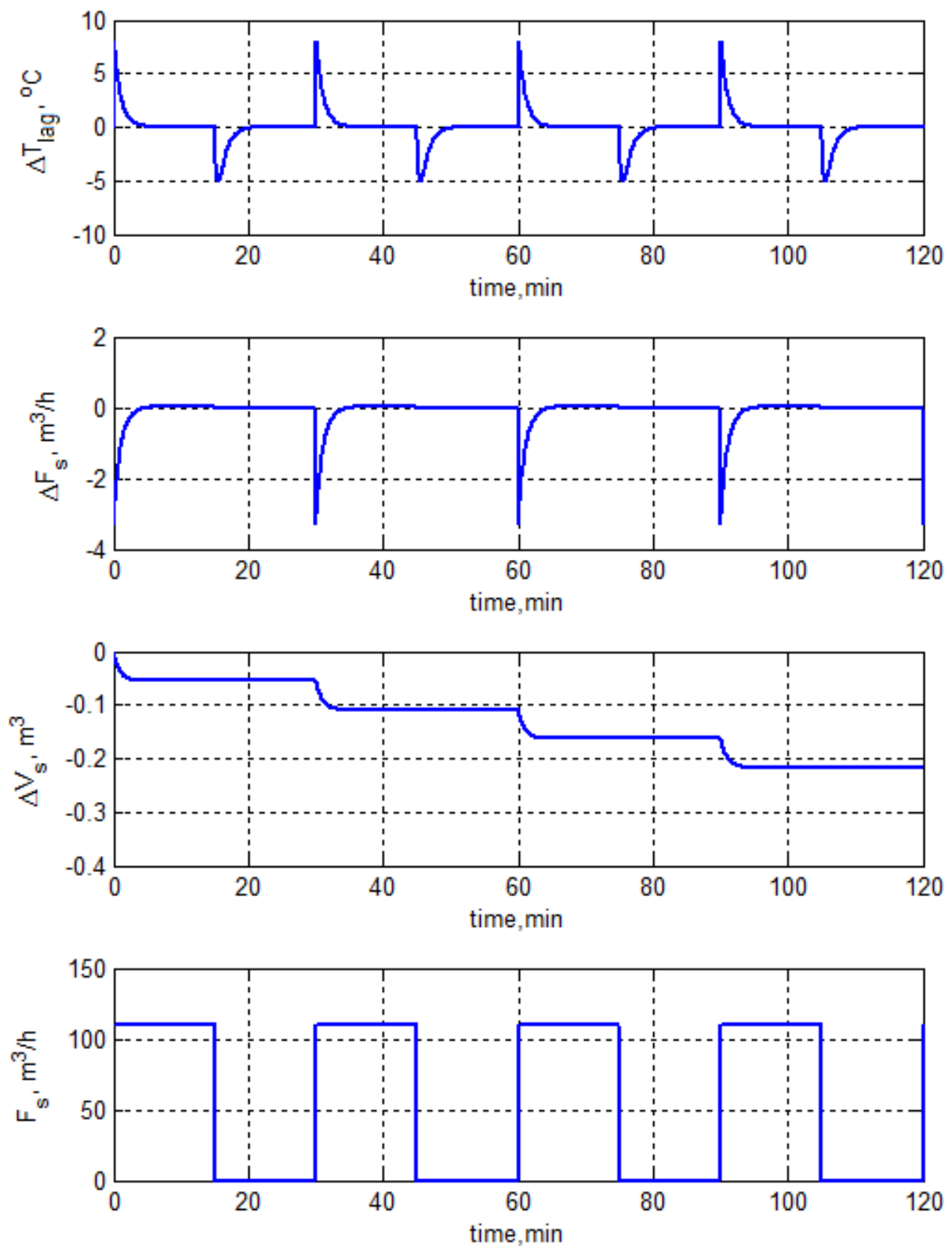

Fig. 4. Variation of the gas flow rate and the errors $\Delta T_{\text {lag }}, \Delta F_{s}$, and $\Delta V_{s}$

For the unit being analysed, the measured value of the gas volume is underestimated by $0.22 \mathrm{~m}^{3}$ in 2 hours and by $2.67 \mathrm{~m}^{3}$ in one day. The modelling was also carried out for the other modes of gas flow. In case when the duration of impulses and pauses is $10 \mathrm{~min}$ instead of $15 \mathrm{~min}$, the underestimation will reach $4.10 \mathrm{~m}^{3}$ per day. And if the time constant of the temperature transducer is $1.5 \mathrm{~min}$ (for the duration of impulses and pauses being $15 \mathrm{~min}$ ), the underestimation will be $4.01 \mathrm{~m}^{3}$. For the duration of impulses and pauses being $10 \mathrm{~min}$ and the time constant of the temperature transducer being $1.5 \mathrm{~min}$, the measured volume will be underestimated by $6.09 \mathrm{~m}^{3}$ per day.

\subsection{Analysis of impulse modes of gas consumption by heat-generating equipment}

Industrial water-heating boilers and steam generators often consume gas in an impulse mode, i.e. gas is supplied to the burner discretely at a certain fixed flow rate. The period of the gas flow rate impulses, as well as their duration depends on the following factors:

- Heat consumption mode (hot water, steam, etc.). It has an influence on the load of the boiler. A change in the boiler load results in a changed period of the gas flow rate impulses and their changed duration.

- The settings of the temperature controller. The dead band width for the two-point temperature controller determines the frequency of turning on and off and influences the parameters of the gas flow rate impulses.

- The gas flow rate at the burner. Its value is set by the position of the valve in the gas feeding line: the higher the gas flow rate is, the shorter the duration of the flow rate impulses is. 
- Ventilation of the combustion chamber. Prior to turning on gas feeding into the burner, the combustion chamber must be ventilated to remove the residual gas and to prevent a possible blast. The duration of ventilation depends on the capacity of the blower fan and the volume of the combustion chamber and the chimney. The duration of ventilation can be 2 to $7 \mathrm{~min}$. The longer the ventilation duration is, the longer the intervals between the gas flow rate impulses are.

In addition to the above-listed factors, the frequency of the gas flow rate impulses, as well as the duration of the impulses, depend on the dynamic characteristics of heat generating equipment.

\section{Conclusion}

The temperature transducer lag can have a significant effect on the accuracy of gas metering in impulse modes of operation. Based on the modelling it was defined that in the conditions when the gas flow temperature is lower than the ambient temperature in the boiler house $\left(T_{\text {gas }}<T_{\text {air }}\right)$, the error of measurement of the gas volume, due to the temperature transducer lag, is negative. The value of the error depends on the temperature transducer lag (time constant), gas flow rate, difference between the temperature of the gas and the ambient temperature, and the period of the gas flow rate impulses. For the natural gas metering unit being analysed, the temperature transducer lag at impulse modes of the flow can lead to the gas metering underestimation amounting to $6 \mathrm{~m}^{3}$ per day, which makes $180 \mathrm{~m}^{3}$ per month.

The error $\Delta T_{\text {lag }}$ can be reduced by taking the following measures: installation of low-lag temperature transducers directly in the gas flow; placement of gas metering units in the conditions in which the gas flow temperature is equal to the ambient temperature; setting the continuous mode of gas flow through the metering unit if it is allowed for the technological process.

The proposed method of defining and minimizing the error of gas temperature and volume measurement which is caused by the temperature transducer lag at impulse modes of gas flow in the metering system will ensure the improvement of accuracy of natural gas volume measurement.

The next steps in our research will be to analyze not only $\Delta T_{\text {lag }}$ error but other errors caused by heat exchange processes (i.e. $\Delta T_{T}, \Delta T_{x}, \Delta T_{t h r}$ ) and their combined effect on the accuracy of natural gas volume measurement for an acting gas metering system.

\section{References}

[1] Fedoryshyn, R.; Matiko, F. \& Pistun, Y. (2008). Prospects for Improving the Accuracy of Natural Gas Accounting and for Reducing Gas Unbalances (2008). 0485-0486, Annals of DAAAM for 2008 \& Proceedings of the 19th International DAAAM Symposium, ISBN 978-3-901509-68-1, ISSN 1726-9679, pp. 243, Editor B. Katalinic, Published by DAAAM International, Vienna, Austria 2008.

[2] Y. Pistun, F. Matiko, R. Fedoryshyn. (2010). Influence of heat exchange processes on the accuracy of natural gas volume measurement // Metrology and Instruments. - Kharkiv National University of Radio Electronics. No 4(24). - pp. 13-19.

[3] Lichko, A.A., Nesterenko, B.N., Suslov, V.Y. (2004). Consideration and reduction of the effect of the temperature difference between the gas and ambient air on the meter readings //Proceedings of the 19th International Scientific and Practical Conference Commercial Metering of Energy Carriers - St. Petersburg, 20-22 April, 2004. pp. 130-135.

[4] Volosianko, V.D., Volosianko, L.S. (2002) The unaccounted influence of the temperature factor on the accuracy of natural gas flow metering // Oil and Gas Industry. No 6. pp. 45-47.

[5] Y. Pistun, F. Matiko and R. Fedoryshyn. (2012). Additional Error of Flow Temperature Measurement and Its Influence on the Accuracy of Fluid Flowrate and Volume Measurement // Proceedings of 8th International Symposium on Fluid Flow Measurement, June 20-22, 2012, CDROM version, pp.1-18, Colorado Springs, Colorado, USA

[6] Labay, V.Y. (2004). Heat and mass transfer: Textbook for higher educational institutions. - Lviv: Triada Plus Publishers. $-260 \mathrm{p}$.

[7] Krivoshein, B.L. (1982). Thermophysical calculations of gas pipelines. - M., Nedra Publishers, 168 p.

[8] Stensel, Y.I. (1993) Mathematical modelling of technological objects of control: Tutorial. - K.: ISDO. - 328 p.

[9] MVU 034/03-2008. Volume of natural gas at standard conditions. Typical technique of measurement by means of a gas meter and a corrector of gas volume. Ukrmetrteststandart, Kyiv, 2008.

[10] GOST 30319.1 - 96. Natural gas. Methods for calculating the physical properties. 